scrupulously clean, dry, and protected from physical trauma. Anal cleanliness has been a preoccupation of man from time immemorial. The art is practised with greater care, cunning, and tradition in tropical and subtropical climes than it is in Britain. I have heard an eminent American physiologist observe that the reason why most Englishmen looked so miserable was because they had perianal soreness from their habit of using tracing paper for postdefecation cleansing, whereas the French were a happier looking race because of their almost universal use of the bidet. Certainly the French have long been aware of the evil consequences of poor perianal hygiene. The notorious François Rabelais wrote a verse in about 1520 :

St Anthony's fire sieze on thy toane,

If thy Dirty Dounby Thou dost not wipe, ere thou be gone.

If, then, perianal cleanliness is a prerequisite to the control of pruritus ani cleanliness should be achieved with the minimum of trauma. Dry wiping of the skin is much more likely to traumatise than wiping with wet material; ideally one should wash gently with a jet of water, a moist cloth, or cotton wool. Wet wiping of the perianal skin is also much more efficient than dry wiping. The truth of this statement can be observed quite simply by sufferers and non-sufferers alike. If the anus is cleaned efficiently and gently with soft dry tissues and then when apparently clean it is wiped again using moist tissue such as "Wet Ones" or "Baby Wipes" most adults will observe that a recognisable amount of faecal material is removed after apparent complete cleanliness with a dry wipe. Once this observation has been shown to sufferers from pruritus ani they will easily be persuaded always to carry sachets or drums of wet wipes with them when they travel and particularly if they have to defecate away from home and washing facilities. This is particularly important in those people who habitually defecate after they arrive at work in the morning.

Conditions which predispose to faecal leakage make anal cleanliness particularly difficult. The elderly, particularly women, and women who have suffered damage from parturition are most likely to have minor or major degrees of incontinence. Is it ever worth while trying to improve their continence in the management of pruritus ani ? Certainly those in whom the incontinence is in itself a major symptom require treatment. The specialist has at his command measures designed to improve the function of the anal sphincter such as physiotherapy with exercises or faradic stimulation and the use of portable self treatment devices with anal sphincter stimulators. Anecdotal evidence suggests that these sometimes relieve symptoms in patients with pruritus ani, but scientific proof from prospective trials is lacking. I am sure that measures to improve the power of the anal sphincter are much less important in the management of pruritus than attention to hygiene. Nevertheless, patients with true incontinence who can be cured or improved are often delighted to have their anal irritation relieved. On the other hand I do not believe that surgical intervention (such as a postanal repair of the pelvic floor) is indicated simply to relieve pruritus.

Many patients with pruritus ani are regular imbibers of aperients and this often contributes to their problems. Habitués of liquid paraffin may have a perpetual slight oil leak, while cathartic addicts and bitter beer devotees probably deserve their perianal soreness. I believe-and much of this art is belief rather than science-that a high bran intake is bad for patients with pruritus ani, possibly because of the stool frequency it induces, but possibly also because the minute flakes of bran are particularly difficult to cleanse from the perianal crevices. Nevertheless, in defence of bran fans it must be said that bran makes many people into the satisfied deliverers of what we might call the "normal stool." I remember one of my mentors defining this wholesome objective as "twice round the pan and pointed at both ends." Such happy defecators are rarely troubled by pruritus.

A dry perianal region is next in importance. Sufferers should avoid non-porous clothing and any garments that keep the buttocks held tightly together. Nudism is ideal but, sadly, often impracticable. I have no evidence to confirm or deny the $\stackrel{\vec{F}}{\rightarrow}$ belief that the strict adherence to traditional Scottish kilt wearing is a sure protection against pruritus ani.

To aid in the maintenance of a dry perianal region the local application of astringent lotions is particularly helpful when dermatitis produces skin exudation. The ancient Egyptians used infusions of acacia leaves for their perianal problems. $\overrightarrow{0}$ Possibly a more reliable but more expensive application is a $\overrightarrow{\vec{H}}$ $0.5 \%$ aqueous solution of silver nitrate. This readily oxidises in $\vec{\omega}$ light, however, and needs to be prepared fresh once or twice a $\frac{\sigma}{3}$ week; it also stains the fingers. Antifungal agents are useful if there is the characteristic "prairie fire" edge to the dermatitis indicating a fungal origin. Occasionally they may induce local irritation and sensitivity, so some dermatologists recommend $\mathbb{W}_{\infty}$ older, cheaper, less elegant lotions such as aqueous solution of pig magenta co.

Probably the single most effective measure in the control of 을 pruritus ani is the education of the patient in the nature of the $\vec{\overrightarrow{ }}$ condition and the rationale of its control. Like many busy $c$ proctologists I have prepared a printed handout with a list of $\stackrel{\bigodot}{\gtrless}$ do's and don'ts. This allows the patient to refer to the $\vec{\varphi}$ instructions at leisure and to read it again whenever there is a recrudescence.

\section{J ALEXANDER-WILLIAMS}

Consultant Surgeon

General Hospital

Birmingham B4 6NH

\section{Dyspnoea}

Difficulties in breathing comprise a variety of sensations which patients describe with an even greater variety of words. Merseysiders, remembering the days of the great transatlantic liners, talk about "blowing for tugs," while others complain of having to breathe too much, of not being able to breathe enough, of needing to take deep breaths, of gasping, suffocation, or tightness in the chest or throat. All these expressions have in common undue awareness of a function which is normally subconscious and of a discomfort which is not commensurate with the level of physical activity.

Probably no single mechanism or pathway is responsible for the sensation of dyspnoea. The classic experiments of Fowler ${ }^{1}$ and Campbell et $a l^{2}$ showed that the discomfort associated with holding the breath was not related to blood gas concentrations nor to stimuli from the lung but probably arose from receptors in the chest wall. Campbell and Howell ${ }^{3}$ postulated that the principal cause of dyspnoea was a mismatch between the tension set up in the respiratory muscles by stimuli from the brain and the resulting change in muscle length (length-tension inappropriateness). Vagal afferents may also contribute to the sensation of dyspnoea, ${ }^{4}$ perhaps from 
stimulation of $\mathrm{J}$ receptors in the lung ${ }^{5}$-as may occur in pulmonary oedema and interstitial fibrosis. A third mechanism was proposed by Roussos and Macklem, ${ }^{6}$ who found that patients breathing against mechanical loads could not sustain high transdiaphragmatic pressures indefinitely; possibly fatigue of the respiratory muscles may play a part in the discomfort of dyspnoea.

Dyspnoea may result from increased demand, faulty performance, or a combination of the two. An increased demand for breathing may be physiological (exercise, high altitude, pregnancy) or pathological (anaemia, hyperthyroidism, metabolic acidosis). Faulty performance may be due to neuromuscular causes, mechanical defects in the thoracic cage, obstruction to air flow, abnormal stiffness of the lungs, or impaired gas exchange. These conditions do not always cause dyspnoea proportionate to the severity of the respiratory disorder. For example, the hyperventilation of acidosis, however dramatic as a physical sign, may be unaccompanied by dyspnoea if the patient has healthy lungs or if consciousness is blunted; and serious reduction in respiratory reserve can develop without dyspnoea if the patient is sedentary. The perception of dyspnoea among asthmatics is very variable: patients with obstruction to air flow that is either persistent or frequently acute may acquire a degree of tolerance (temporal adaptation) which reduces the intensity of the sensory experience $^{i}$ and thus masks the gravity of their condition. Patients with chronic bronchitis and emphysema, too, may have differing levels of dyspnoea for the same degree of air flow obstruction: "blue bloaters" with chronic hypercapnia and a diminished urge to breathe seem less breathless than "pink puffers," whose vigorous respiratory efforts keep their blood gas values normal. ${ }^{8}$ Recently, however, it has been suggested that this difference in disability is more apparent than real. ${ }^{9}$

The intensity of dyspnoea ultimately depends on the mental interpretation of the cerebral stimuli, and this, too, inevitably varies from one person to another. In a recent study of patients with chronic bronchitis, ${ }^{10}$ attitudes and beliefs outweighed measurements of ventilatory capacity in predicting performance in an exercise test.

Despite new techniques for the objective assessment of dyspnoea, history and clinical observation are still of great importance. Dyspnoea on exertion should be graded according to the amount of exercise needed to induce it. The sudden onset of dyspnoea at rest is usually due to left heart failure, pneumothorax, pulmonary embolism, asthma, acute pneumonia, or sudden occlusion of a large airway. Paroxysmal nocturnal dyspnoea or orthopnoea suggests a cardiac cause, but asthma also may occur during the night (early morning dippers), and paralysis of the diaphragm is a less well recognised cause of orthopnoea. Dyspnoea provoked by emotional causes or exposure to allergens and dyspnoea occurring after rather than during exercise are characteristic of asthma.

The rate, depth, and rhythm of respiration, any deformity of the thoracic cage, and the presence of abnormal movements -lip pursing, accessory muscle activity, or paradoxical movement of the chest wall-must all be noted. Relevant extrathoracic observations include cyanosis, signs of cardiac failure or hypercapnia (drowsiness, flapping tremor), finger clubbing, and evidence of venous thrombosis in the legs. The physician should also listen to the patient's breathing, which cannot be heard at a distance of more than a foot in a healthy person at rest. Audible breathing is usually due to obstruction to air flow or hyperventilation. Forced inspiration and expiration may respectively produce stridor and wheeze which were not apparent at rest. The hissing respirations of acidosis (Kussmaul's breathing), the occasional sighs of the anxious patient, and the rattling sound of secretions in the airway of a patient too weak to cough are all more readily detected by the naked ear than through a stethoscope. Only when these observations have been made should the stethoscope be used to seek the expiratory wheeze of air flow obstruction, the inspiratory crackles of alveolitis or pulmonary oedema, the signs of collapse, consolidation, effusion, or pneumothorax, and any relevant abnormality in the heart. Finally, the patient should be examined under the conditions in which he usually experiences dyspnoea: during and after exercise, on lying flat, or-with suitable precautions-when exposed to a suspected allergen or other specific provoking factor.

The investigation of the breathless patient is designed to show both the severity and the cause of the disability. In addition to chest radiography, an electrocardiogram, measurement of haemoglobin concentration, and standard lung function tests with blood gas analysis, exercise testing is of prime importance. ${ }^{112}$ This can be performed with degrees of refinement ranging from measurement of the distance walked in a set time ${ }^{13}$ to comprehensive respiratory, circulatory, and metabolic analyses during graded exercise. The exercise tests most widely used for the investigation of dyspnoea in the laboratory are those in which measurements are made during incremental exercise on a cycle ergometer or treadmill. Information is derived from non-invasive recordings of tidal volume, respiratory rate, expiratory flow patterns, oxygen uptake, carbon dioxide output, heart rate and rhythm, electrocardiographic changes, and arterial oxygen saturation measured by ear oximetry; blood sampling during exercise can provide additional metabolic data such as $\mathrm{pH}$, blood gas tensions, and blood lactate concentrations. These tests (which are safe if cardiac performance is closely monitored) give a measure of maximum exercise capacity and also help to determine whether the limiting factors are cardiovascular, respiratory, or psychogenic. $^{14}$

Colin Ogilvie

Consultant Physician,

Royal Liverpool Hospital,

Liverpool L7 8XP

${ }^{1}$ Fowler WS. Breaking point of breath-holding. I Appl Physiol 1954;6: 539-45.

${ }^{2}$ Campbell EJM, Freedman S, Clark TJH, Robson JG, Norman J. The effect of muscular paralysis induced by tubocurarine on the duration avd sensation of breath-holding. Clin Sci 1967;32:425-32.

${ }^{3}$ Campbell EJM, Howell JBL. The sensation of breathlessness. Br Med Bull 1963;19:36-40.

' Guz A, Noble MIM, Eisele JH, Trenchard D. Experimental results of vagal block in cardiopulmonary disease. In: Porter R, ed. Breathing: Hering-Breure centenary symposium. London: Churchill, 1970:315-36.

${ }^{5}$ Paintal AS. Mechanism of stimulation of type J pulmonary receptors. f Physiol (Lond) $1969 ; 203: 511-32$.

${ }^{6}$ Roussos CS, Macklem PT. Diaphragmatic fatigue in man. 7 Appl Physiol 1977;43:189-97.

${ }^{7}$ Burdon JGW, Juniper EF, Killian KJ, Hargreave FE, Campbell EJM. The perception of breathlessness in asthma. Am Rev Respir Dis 1982; $126: 825-8$.

${ }^{x}$ Fishman AP, Ledie JF. Dyspnea. Bull Eur Physiopathol Respir 1979;15: 789-804.

9 Johnson MA, Woodcock AA, Rehahn M, Geddes DM. Are "pink puffers" more breathless than "blue bloaters ?" $B r$ Med f 1983;286:179-82.

${ }^{10}$ Morgan AD, Peck DF, Buchanan DR, McHardy GJR. Effect of attitudes and beliefs on exercise tolerance in chronic bronchitis. $\mathrm{Br} \mathrm{Med} \mathcal{F}$ $1983 ; 286: 171-3$.

${ }^{11}$ Jones NL, Campbell EJM. Clinical exercise testing. 2nd ed. Philadelphia: Saunders Company, 1982

${ }^{12}$ Wasserman K, Whipp BJ. Exercise physiology in health and disease. Am Rev Respir Dis 1975;112:219-49.

${ }^{13}$ McGavin CR, Gupta SP, McHardy GJR. Twelve-minute walking test for assessing disability in chronic bronchitis. Br Med f 1976; i :822-3.

1.1 Wasserman $\mathrm{K}$. Dyspnea on exertion. Is it the heart or lungs? $\mathcal{f} A M A$ $1982 ; 248: 2039-43$. 